\title{
RESISTANCE VARIATION OF CONDUCTIVE INK APPLIED BY SCREEN PRINT TECHNIQUE ON DIFFERENT SUBSTRATES
}

\author{
Pedro Gomes $^{\text {a**, Derya Tama }}{ }^{\mathrm{b}}$, Hélder Carvalho ${ }^{\mathrm{a}}$ and António Pedro Souto ${ }^{\mathrm{a}}$ \\ ${ }^{a} 2 C 2 T$ - Centro de Ciência e Tecnologia Têxtil, Universidade do Minho, Campus de Azurém, 4800- \\ 058 Guimarães, Portugal \\ $l^{b}$ Ege University / Department of Textile Engineering / 35100 Bornova / Izmir, Turkey \\ *corresponding authorvpcgomes@gmail.com
}

\begin{abstract}
This research focused on the application of conductive ink by the screen printing technique to evaluate the potential of creating printed electrodes and investigating the effect of washing on the values of electrical resistance and flexibility. Within the scope of this, two conductive inks from Dupont, applied by conventional screen printing method, on four different textile substrates, $100 \%$ cotton, 50/50 cotton/polyester, $100 \%$ polyester and $100 \%$ polyamide. The inks were also applied on a multifibre fabric. Atmospheric plasma treatment was applied in order to improve the adhesion to the samples, and the resistance values were compared with non-treated samples on the different fibres. The values were measured before and after cleaning and washing tests, performed to simulate home treatment for garments, in order to predict the behaviour of the inks after a normal usage of the fabrics. Comfort properties like stiffness of the fabrics were also evaluated after 5 and 10 washing cycles. It was observed that the PE 825 ink forms a thicker film on the fabric surface contributing to the loss of flexibility of the textile. However, it also resulted in the best results in terms of durability and lower values of resistance in general. PA fabrics lost their conductive property after 5 washing cycles due to a weak bonding created between the ink and the fibres, whereas the cotton fibres presented the best results.
\end{abstract}

\section{Key Terms}

Conductive ink, Smart garments, Screen print, Washing fastness

\section{Introduction}

Flexible electronic systems applied in textiles are an interesting method used for monitoring position, posture, activity parameters, bioelectrical signals, etc. It is therefore indispensable to obtain compatibility between electronics and fabrics, namely regarding the behaviour when flexed or stretched [1].

There are applications and researches about different flexible materials as well as methods to achieve flexible electronic systems. Transferring conductive pastes onto textile substrates is one of the research topics in this area, with a significant range of studies exploring ways to achieve this. Although there are several attempts by inkjet printing [2-4], most of the researches have focused on screen printing [1, 5-16] due to its low cost. Systems capable of measuring heart rate or breathing movement, or capable of accumulating energy from the body or the environment (sun, rain), can be achieved by these methods [5]. In these systems, conductive patterns are created in a predetermined area instead of coating the entire textile surface [7]. Different applications can be created depending on the final objective of the sensor such as stretch [2], electrocardiography monitoring [6,7,12,16], pressure [10, 17], healthcare [8,9], tribo-sensors [11], supercapacitors [13] and solar cells [14,15].

The durability, namely washability of these electronic systems are now outstanding issues. Ankhili et al. [7] highlighted that the reliability and washability of electronic systems are the key issues that have to be investigated in order to develop a commercial product. Therefore, they have focused on developing textile electrodes to be used for long-term 
electrocardiography measurements, to sustain up to 50 washing cycles. Ran et al. [11], evaluated the resistance change according to bending degree as well as the washing cycles. The electrode was immersed in water for 10 times and 2 hours at each time. Yang et al. [8] developed a user-friendly electronic sleeve for wearable healthcare and evaluated cleaning methods to enable reuse after contamination during use. They have assessed the bacterial level using wiping method with 3 different wipes and washing method simulating a quick daily washing program.

The application of conductive ink by the screen printing technique described in this work is intended to evaluate the potential to create electrical circuit networks to be used to carry electrical signals in clothing or technical applications where pressure sensors, previously developed $[18,19]$, were applied. In order to evaluate the efficiency of the application, Dupont PE 828 and PE 825 inks were applied on different textile substrates. Atmospheric plasma treatment was applied to the textile substrates before the application of conductive inks in order to improve the adhesion between the inks and the substrate. The use of plasma treatment of textiles is a dry, environmentally- and worker-friendly method [20], which is achieved via surface alteration without modifying the bulk properties of the materials [21]. It is faster and more environmentally friendly than chemical surface modification techniques [22].

This research also focused on evaluating the effect of washing on the values of electrical resistance and flexibility of the material. The washing method used were 10 standard household washing cycles and the parameters studied were measured before washing and after the $5^{\text {th }}$ and the $10^{\text {th }}$ cycle. The existing researches about washability of printed electrodes are focused on the durability after different counts of washing cycles. However, they have not concentrated on comparing different textile substrates. Therefore, we believe this study will contribute to the state-of-the-art.

\section{Experimental}

\subsection{Materials}

\section{Fabrics}

Commercial $100 \%$ polyester (PES), $100 \%$ polyamide (PA), $100 \%$ cotton (CO) and 50/50 $\mathrm{CO} / \mathrm{PES}$, plain weave fabrics with a weight per unit area of $110 \mathrm{~g} / \mathrm{m}^{2}$, were used in this study. The fabrics were pre-washed with $1 \mathrm{~g} / \mathrm{L}$ of a non-ionic detergent solution at $60^{\circ} \mathrm{C}$ for $60 \mathrm{~min}$, in order to eliminate possible contaminations. Commercial SDCE multifibre DW fabric was also used, a product acquired from SDC Enterprises Ltd (United Kingdom).

\section{Conductive inks}

Two conductive inks (DuPont PE 825 Silver Composite Conductor and DuPont PE 828 Silver Conductor) were used as conductive material to create the electrical connections. DuPont PE 825 Silver Composite Conductor is used to fabricate low-voltage circuitry, on flexible substrates including polyester film. It has a curing condition of $120^{\circ} \mathrm{C}-140^{\circ} \mathrm{C}$ during $2-10$ minutes. The density of the original paste is $2,6 \mathrm{~g} / \mathrm{cc}$ and the coverage is $180 \mathrm{~cm}^{2} / \mathrm{g}$ at $10 \mu \mathrm{m}$. PE 825 is presented as a highly efficient silver-bearing conductor that possesses excellent abrasion resistance, adhesion and print resolution. DuPont PE 828 is a low temperature drying Silver Conductor, designed to maintain low temperature substrate tolerances as this composition can be applied between $60^{\circ} \mathrm{C}$ and $100^{\circ} \mathrm{C}$, for $10-20$ minutes. PE 828 has the density as $2,5 \mathrm{~g} / \mathrm{cc}$ and the coverage as $200 \mathrm{~cm}^{2} / \mathrm{g}$ at $10 \mu \mathrm{m}$.

The inks were applied directly to the substrate without the addition of fixation elements external to the original paste.

\subsection{Procedures}




\section{Plasma treatment}

Atmospheric plasma treatment was applied in order to improve the adhesion between the inks and the substrate, through the creation of micro roughnesses on the surface of the textile substrate, creating a larger contact surface for more effective adhesion of the ink [23]. The plasma treatment was performed in a semi-industrial prototype machine (Softal $\mathrm{GmbH} / \mathrm{University}$ of Minho) at room temperature and atmospheric pressure, using a system of metal electrode coated with ceramic and counter electrodes coated with silicone with $50 \mathrm{~cm}$ effective width and a fixed gap distance of $3 \mathrm{~mm}$. They produce a discharge of $10 \mathrm{kV}$ at 40 $\mathrm{kHz}$. A power of $1 \mathrm{~kW}$ was applied, with a speed of $4 \mathrm{~m} / \mathrm{min}$, each sample passing 5 times per side. The total applied dosage was $5 \mathrm{~kW} \mathrm{~min} / \mathrm{m}^{2}$.

\section{Screen print}

The process for the application of the conductive inks was carried out in a Zimmer samples stamping machine using a conventional screen printing method. Two passes were made (one for each side), with maximum magnetic force used. The screen used was a $100 \mathrm{thread} / \mathrm{cm}$ polyester mesh. Connections of $10 \mathrm{~cm}$ length by $0.5 \mathrm{~cm}$ width were made (Figure 1). After the ink application the samples were cured at $120^{\circ} \mathrm{C}$ for 10 minutes for the $\mathrm{PE} 825$ and at $80^{\circ} \mathrm{C}$ for 20 minutes for the PE 828 ink.

Figure 1 Conductive samples

\section{Washing test}

To assess the resistance to washing, ISO 105-C06 A2S tests were performed in a Roaches washtec-p machine, to determine the resistance to all forms of domestic or commercial laundering procedures. The samples were washed 10 times each, at a temperature of $40^{\circ} \mathrm{C}$ during 30 minutes with 10 steel spheres for a single test.

\subsection{Analytical Methods}

\section{Stiffness test}

To test the influence of the conductive ink on the stiffness of the textile material, a stiffness test was carried out on a Shirley TF113 fabric stiffness tester. The stiffness test is capable of determining the bending height, flexural rigidity and bending modulus of fabric by simple procedures and calculation. The method complies with ASTM D1388. The test was carried out at 0 (0ws), 5 (5ws) and 10 washing cycles (10ws).

\section{Electrical resistance test}

The electrical resistance values were measured with a Fluke 45 multimeter with a measurement range up to $100 \mathrm{M} \Omega$. The measurements were taken with a distance of $4 \mathrm{~cm}$ between the test leads for the 100\% CO, 50/50 CO/PES, 100\% PES and 100\% PA fabrics, and a distance of 1 $\mathrm{cm}$ in the multifibre fabric, due to the maximum size of the fibres in the multifibre fabric. The tests were carried out at $0 \mathrm{ws}, 5 \mathrm{ws}$ and $10 \mathrm{ws}$ and the change in electrical resistance after the washing cycles were recorded.

\section{Microscopic analysis}

After the washing processes, the conductive track was evaluated using a Leica DM $750 \mathrm{M}$ optical microscope using $5 \times 10$ times magnification, so that it was easier to identify changes in the surface of the applied material, like cracks and wear.

\section{Results and Discussion}




\section{Stiffness test}

After the screen print application of the inks, the fabrics were tested to evaluate the change in flexibility in the fabric and then compared after 5 and 10 washes (Table I).

Table I Stiffness test

Samples produced with 825 ink presented a high rigidity after the application and it was not possible to obtain a value on the scale for the pre-wash test. However, after the first wash the stiffness value decreased, allowing to obtain measurable results. After 5ws the 825 ink still presented higher values of stiffness then the 828 , after the $10 \mathrm{ws}$ the values tended to be similar. It is a fact that, coated fabrics behave much differently from uncoated fabrics during deformation [24]. This explains the change in stiffness of printed substrates by washing and it is possible to confirm a trend of decreasing stiffness throughout the application of the washing for all the samples. Only the PA samples contradicted with this trend and showed a slight increase or maintenance of the values. Application of plasma treatment to the samples resulted in lower values of rigidity due to its increasing effect on adhesion of ink onto substrate.

\section{Electrical resistance test}

Resistance values were measured for each sample, before washing, after 5 and 10 washing cycles, and are compiled in Table II. When resistance values were out of range, the sample was considered as non-conductive (NC).

Table II Resistance value of conductive tracks on fabrics, in ohm

After the tests, the 825 ink presented the best results in terms of durability and lower values of resistance. Patterns of behaviour within the different groups of fibres can also be found. PA fabrics lost the conductive property after 5 washes due to a weak bonding between the ink and the fibres. PES samples obtained the lowest value in resistance after 10ws for the 825 ink, (PES plasma 825) but had a tendency to crack, as shown in Figure 2. The samples produced with $100 \% \mathrm{CO}$ and 50/50 CO/PES continued to show conductivity after $10 \mathrm{ws}$, for the 825 ink. According to the results, neither ink adsorption on the samples nor the resistance values showed a clear trend when plasma treatment was applied.

\section{Figure 2 Cracked sample}

Table III presents the results for the multifibre fabric. These samples were measured with a distance of $1 \mathrm{~cm}$. Acetate, Cotton, Polyamide, Polyester, Acrylic and Wool fibres were tested.

Table III Resistance value on multifibre fabrics Ink 825, in ohm

The inks showed good results in the capability to withstand the standard household washing tests and retain the conductive properties after 10 washing cycles. The 825 ink lost the conductive properties in the polyamide sample not treated with plasma.

The thicker structure of the multifibre fabric allowed a better fixation of the inks and at the same time reduced the mechanical stress caused by the cleaning processes, increasing the resistance to the washes.

\section{Microscope analysis}


As analysed before, depending on the ink used, the samples presented different values of flexibility in the pre-wash fabrics. Microscope images were collected (Figure 3) and it was observed that the PE 825 ink forms a thicker film on the fabric surface, contributing to the loss of flexibility of the textile. Plasma treatment increased the penetration capacity of the inks in the $\mathrm{CO}$ fabric resulting in an increase in the electrical resistance value of the sample.

Figure 3 Microscope image of the samples $5 x$ magnified, before wash

After 10 washing cycles (Figure 4) the samples were re-evaluated and new images were collected. The 825 ink still has a high surface coverage, with no ink faults visible in the space between the yarn crossings. In the case of the 828 ink, a loss of conductive material is more visible. Only the fibres that make up the fabric are covered. This leads to a smaller area available for electrical conduction, increasing the resistance and causing the interruption of the flow when the material is folded.

Figure 4 Microscope image of the samples $5 x$ magnified, after 10 washes

Despite having a more uniform area coverage, the PE 825 ink shows greater tendency to form cracks along the connection, as can be observed in Figure 5.

Figure 5 Cracks formation on CO plasma 825 sample $5 x$ magnified

\section{Conclusions}

This study showed that it was possible to use DuPont conductive inks PE 825 and PE 828 to create conductive connections in textile fabrics with conventional screen printing.

The PE 825 ink generally presented the best results in terms of durability and electrical conductivity. The samples printed with the 825 ink presented a high surface coverage even after 10 washing cycles, with no ink faults visible in the space between the yarn crossings, whereas a loss of conductivity was appreciable in the 828 ink printed samples.

Cotton fibres presented the best results. The 100\% CO and the 50/50 CO/PES samples printed with the 825 ink were determined to work even after 10 wash cycles. Supporting this conclusion, in the work conducted by Ankhili et al. [7], the textile substrates were chosen as $100 \% \mathrm{CO}$ and 95/5 CO/Lycra and the authors concluded that pure cotton electrodes could be embedded into garments for long-term ECG monitoring. PES samples with the 825 ink presented the lowest resistance values after 10 washes but tend to break the circuit because of the formation of cracks in the sample. PA fabrics lost their conductive property after 5 washes due to a weak bonding created between the ink and the fibres. Also, in the test made with the multifibre fabric the samples retain the conductive properties after 10 washes. The bulkier fabric contributed to greater stamping resistance.

When a printed electrode is exposed to repeated washing cycles, there is a tendency to adhesion failure between the textile substrate and conductive ink. In order to decrease this effect, Yang et al. [8] used a plastic ball to minimize twisting of the fabric during the washing process. The electrode was put in this plastic wash ball and they observed that, after 8 washing cycles, without encapsulation layer the sample started to crack and lost conductivity while the encapsulated sample remained undamaged.

Application of plasma treatment generated lower values of rigidity in the samples after the washing procedures, but it did not have any encouraging effect on conductivity. 
After the washing process, a stiffness decrease was measured for the acetate, cotton, polyester, acrylic and wool fibres, in the samples tested. Only polyamide fibre didn't follow this behaviour.

\section{Acknowledgements}

This work is financed by Project "Deus ex Machina", NORTE-01-0145-FEDER-000026, funded by CCDRN, through Sistema de Apoio à Investigação Cientifica e Tecnológica (Projetos Estruturados I\&D\&I) of Programa Operacional Regional do Norte, from Portugal 2020 and by Project UID/CTM/00264/2019 of 2C2T - Centro de Ciência e Tecnologia Têxtil, funded by National Founds through FCT/MCTES. Derya Tama thanks FCT for fellowship 2C2T-BPD-08-2017.

\section{References}

[1] Wang Z, Wang W, Jiang Z, Yu D, A novel and simple method of printing flexible conductive circuits on PET fabrics, Applied Surface Science, 396 (2017) Pages 208-213

[2] Bihar E, Roberts T, Ismailova E, Saadaoui M, Isik M, Sanchez AS, Mecerreyes D, Hervé T, Graaf JBD, Malliaras GG, Fully Printed Electrodes on Stretchable Textiles for Long-Term Electrophysiology, Adv. Mater. Technol. 2017, 1600251

[3] Stempien Z, Rybick E, Rybick T, Lesnikowski J, Inkjet-printing deposition of silver electroconductive layers on textile substrates at low sintering temperature by using an aqueous silver ions-containing ink for textronic applications, Sensors and Actuators B, 224 (2016) Pages 714725

[4] Chen JJ, Lin GQ, Wang Y, Sowade E, Baumann RR, Feng ZS, Fabrication of conductive copper patterns using reactive inkjet printing followed by two-step electroless plating, Applied Surface Science, 396 (2017) Pages 202-207, http://dx.doi.org/10.1016/j.apsusc.2016.09.152

[5] Khirotdin RDK, Cheng TS, Mokhtar KA, Printing of conductive ink tracks on textiles using silkscreen printing, ARPN Journal of Engineering and Applied Sciences, 2016, Vol11 (10), Pages 6619-6624

[6] Xu X, Luo M, He P, Guo X, Yang J, Screen printed graphene electrodes on textile for wearable electrocardiogram monitoring, Applied Physics, (2019) 125:714, https://doi.org/10.1007/s00339-019-3006-x

[7] Ankhili A, Tao X, Cochrane C, Koncar V, Coulon D, Tarlet JM, Comparative Study on Conductive Knitted Fabric Electrodes for Long-Term Electrocardiography Monitoring: SilverPlated and PEDOT:PSS Coated Fabrics, Sensors, 2018, 18, 3890; doi:10.3390/s18113890

[8]Yang K, Meadmore K, Freeman C, Grabham N, Hughes AM, Wei Y, Torah R, GlancGostkiewicz M, Beeby S, Tudor J, Development of User-Friendly Wearable Electronic Textiles for Healthcare Applications, Sensors, 2018, 18, 2410; doi:10.3390/s18082410

[9] Noura KI, Horii Y, Kanazawa S, Kusaka Y, Ushijima H, Fabrication of a Textile-Based Wearable Blood Leakage Sensor Using Screen-Offset Printing, Sensors, 2018, 18, 240; doi:10.3390/s18010240

[10] Zhou Z, Li Y, Cheng J, Chen S, Hu R, Yan X, Liao X, Xu C, Yu J, Li L, Supersensitive all-fabric pressure sensors using printed textile electrode arrays for human motion monitoring and human-machine interaction, Journal of Materials Chemistry C, 2018, 6, Pages 1312013127

[11] Cao Ran, Pu X, Du X, Yang W, Wang J, Guo H, Zhao S, Yuan Z, Zhang C, Li C, Wang ZL, Screen-Printed Washable Electronic Textiles as Self-Powered Touch/Gesture Tribo- 
Sensors for Intelligent Human-Machine Interaction, ACS Nano, 2018, 12, Pages 5190-5196, doi: 10.1021/acsnano.8b02477

[12] Sinha SK, Noh Y, Reljin N, Treich GM, Hajeb-Mohammadalipour S, Guo Y, Chon KH, Sotzing GA, Screen-Printed PEDOT:PSS Electrodes on Commercial Finished Textiles for Electrocardiography, ACS Appl. Mater. Interfaces, 2017, 9, Pages 37524-37528, doi: 10.1021/acsami.7b09954

[13] Abdelkader AM, Karim N, Vallés C, Afroj S, Novoselov KS, Yeates SG, Ultraflexible and robust graphene supercapacitors printed on textiles for wearable electronics applications, 2D Mater, 4 (2017) 035016, https://doi.org/10.1088/2053-1583/aa7d71

[14] Liu J, Li Y, Li M, Arumugam S, Beeby SP, Processing of Printed Dye Sensitized Solar Cells on Woven Textiles, IEEE Journal of Photovoltaics, 2019, Vol. 9 (4), Pages 1020-1024, doi: 10.1109/JPHOTOV.2019.2899432

[15] Arumugam S, Li y, Glanc-Gostkiewicz M, Torah RN, Beeby SP, Solution Processed Organic Solar Cells on Textiles, IEEE Journal of Photovoltaics, 2018, Vol. 8 (6), Pages 17101715, doi: 10.1109/JPHOTOV.2018.2871334

[16] Achilli A, Bonfiglio A, Pani D, Design and Characterization of Screen-Printed Textile Electrodes for ECG Monitoring, IEEE Sensors Journal, 2018, Vol. 18 (10), Pages 4097-4107, doi: 10.1109/JSEN.2018.2819202

Pages

[17] Tama D, Gomes P, Abreu MJ, Souto AP, Carvalho H, Developing Smart Body Protector for Sports Karate, 14th International Izmir Textile and Apparel Symposium, 2017, October 2528, Turkey.

[18] Gomes P, Tama D, Yao Y, Abreu MJ, Souto AP, Carvalho H, Development of pressure sensors for smart textiles, IOP Conference Series: Materials Science and Engineering, 2018, 460 (1), 012024

[19] Carvalho H, Tama D, Gomes P, Abreu MJ, Yao Y and Souto AP, Flexible piezoresistive pressure sensors for smart textiles, IOP Conference Series: Materials Science and Engineering, 2018, 459 (1), 012035

[20] Zille A, Oliveira FR, Souto AP, Plasma Treatment in Textile Industry, Plasma Processes and Polymers, 2015, 12, Pages 98-131, doi: 10.1002/ppap.201400052

[21] Choudhary U, Dey E, Bhattacharyya R, Ghosh SK, A brief review on plasma treatment of textile materials, Adv Res Text Eng, 2018, 3(1): 1019.

[22] Ribeiro AI, Senturk D, Silva KK, Modic M, Cvelbar U, Dinescu G, Mitu B, Nikiforov A, Leys C, Kuchakova I, Vrieze MD, Souto AP, Zille A, Antimicrobial Efficacy of Low Concentration PVP-Silver Nanoparticles Deposited on DBD Plasma-Treated Polyamide 6,6 Fabric, Coatings, 2019, 9, 581, doi:10.3390/coatings9090581

[23] Molinaa J, Fernández J, Fernandes M, Souto AP, Esteves MF, Bonastre J, Cases F, Plasma treatment of polyester fabrics to increase the adhesion of reduced graphene oxide, Synthetic Metals, 2015, Vol: 202, Pages 110-122

[24] Sariişik M, Bulut Y, Sülar V, Effects of process parameters on mechanical properties of coated fabrics, International Journal of Clothing Science and Technology, 2011, Vol. 23 (4), Pages 205-221, https://doi.org/10.1108/09556221111136476 


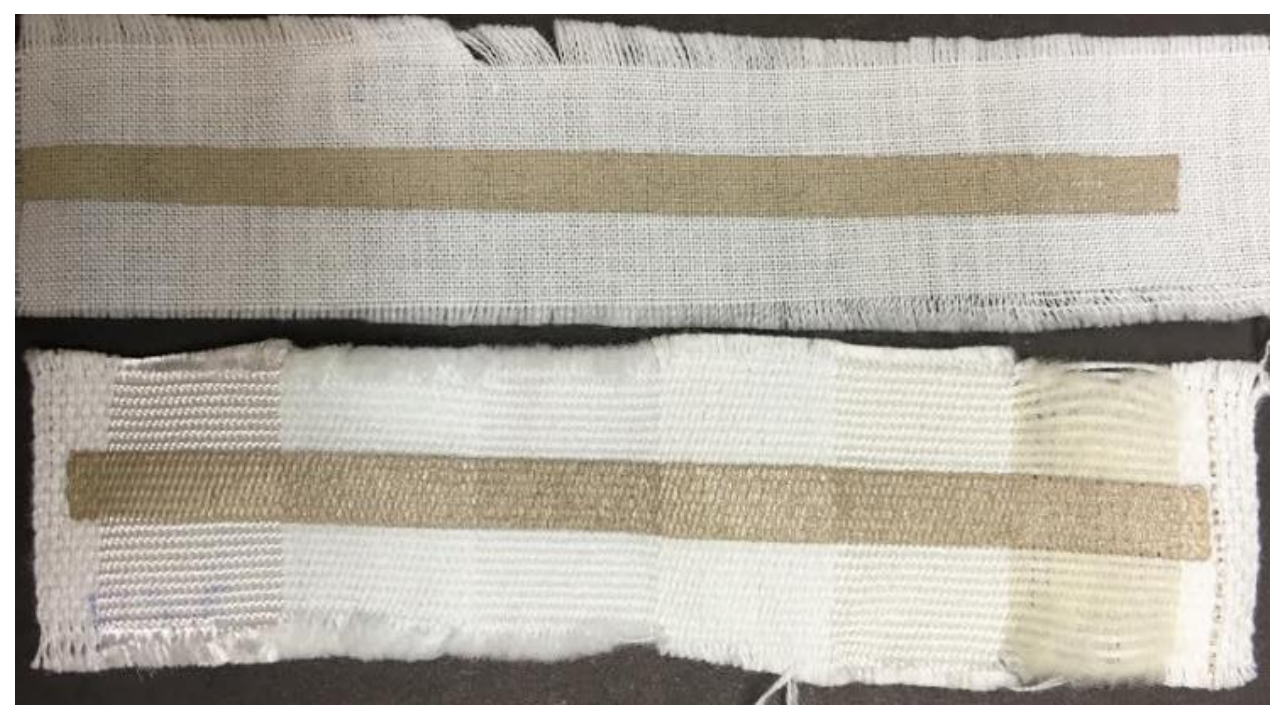

Figure 1 Conductive samples 


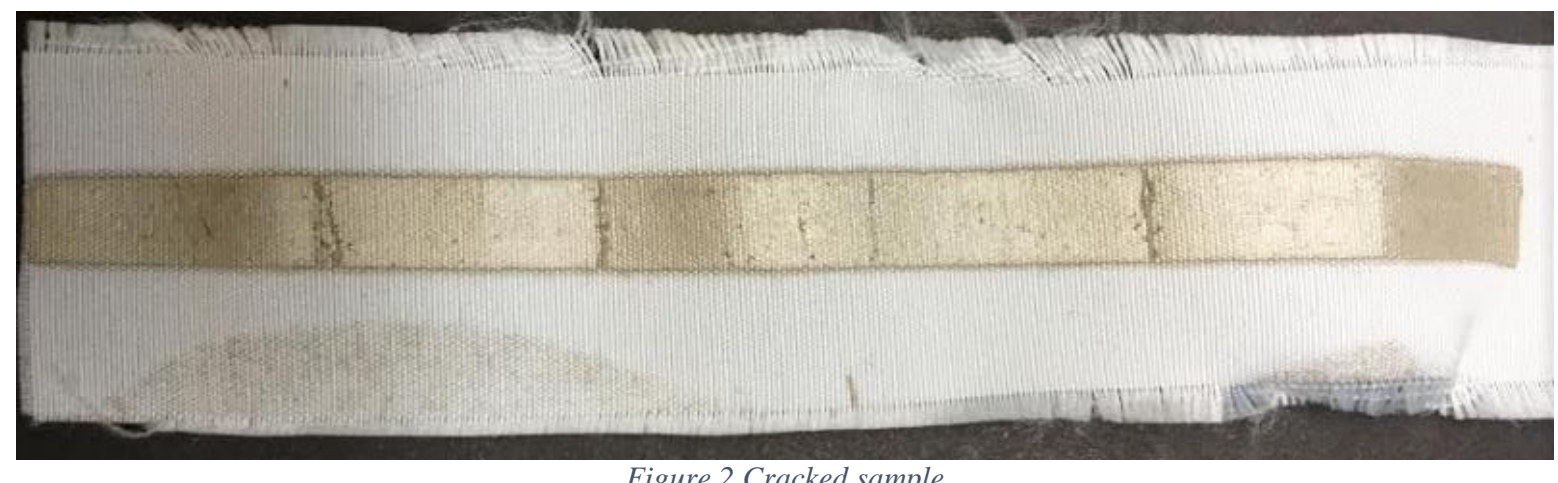

Figure 2 Cracked sample 


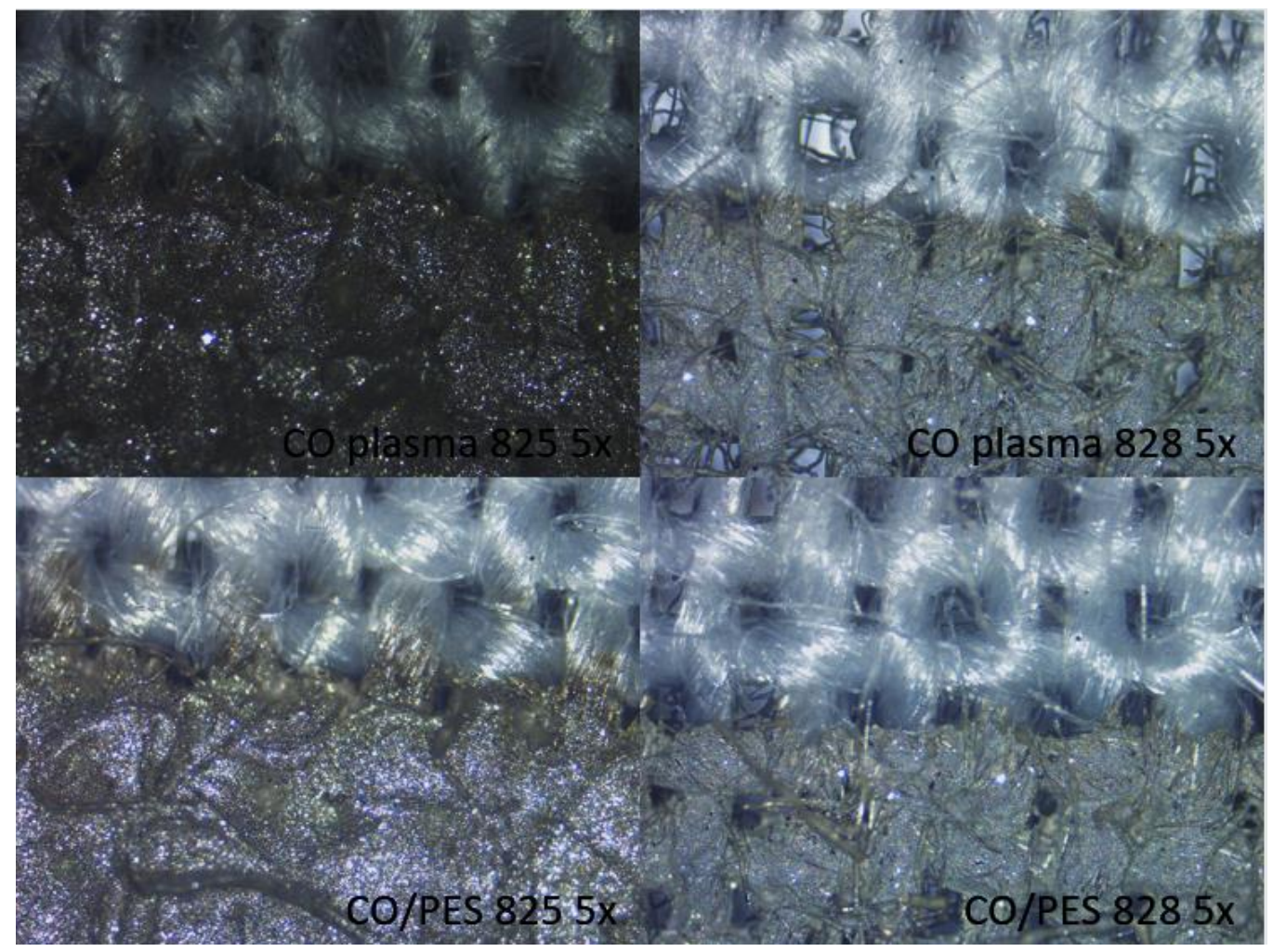

Figure 3 Microscope image of the samples $5 x$ magnified, before wash 


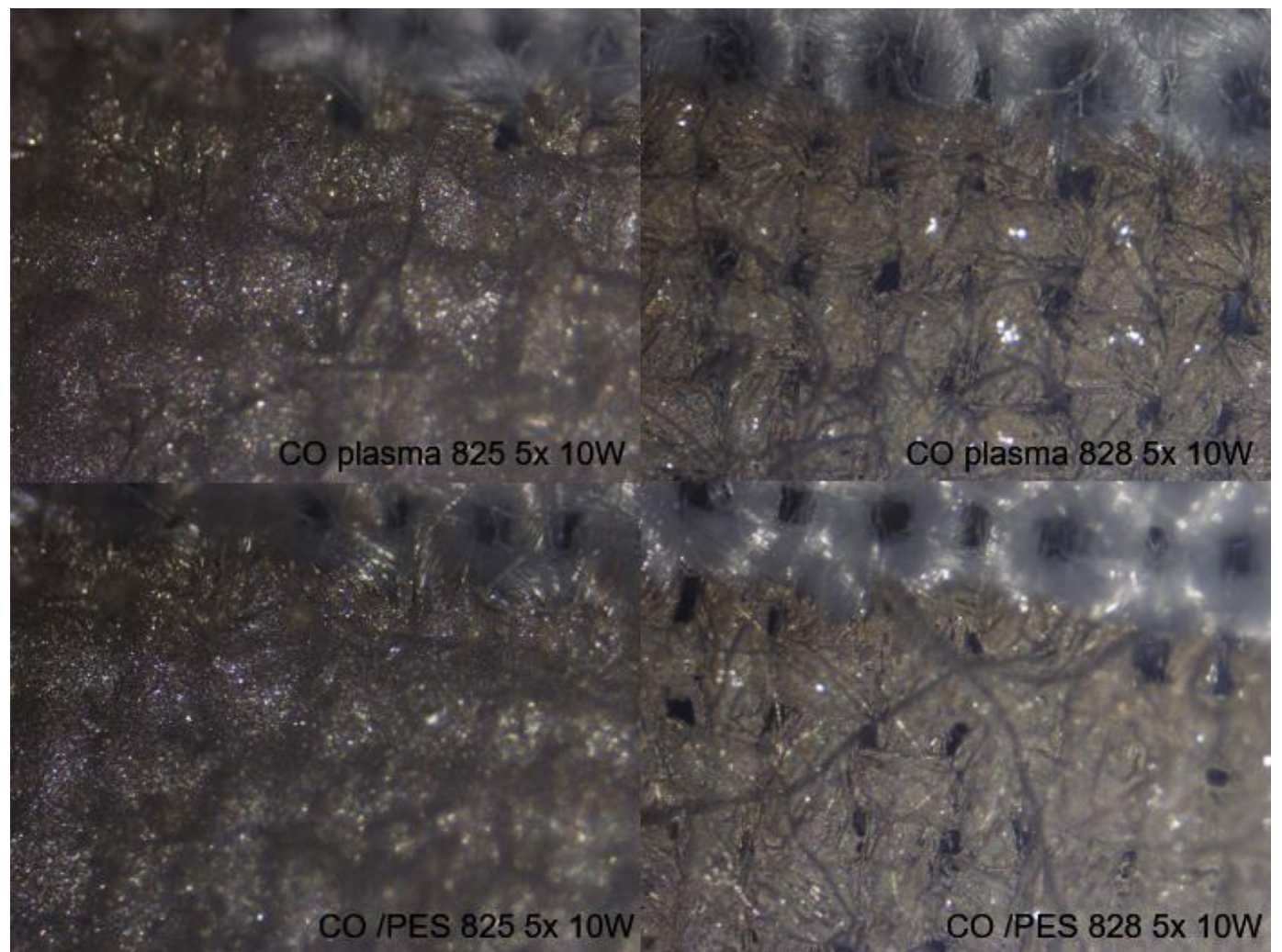

Figure 4 Microscope image of the samples $5 x$ magnified, after 10 washes 


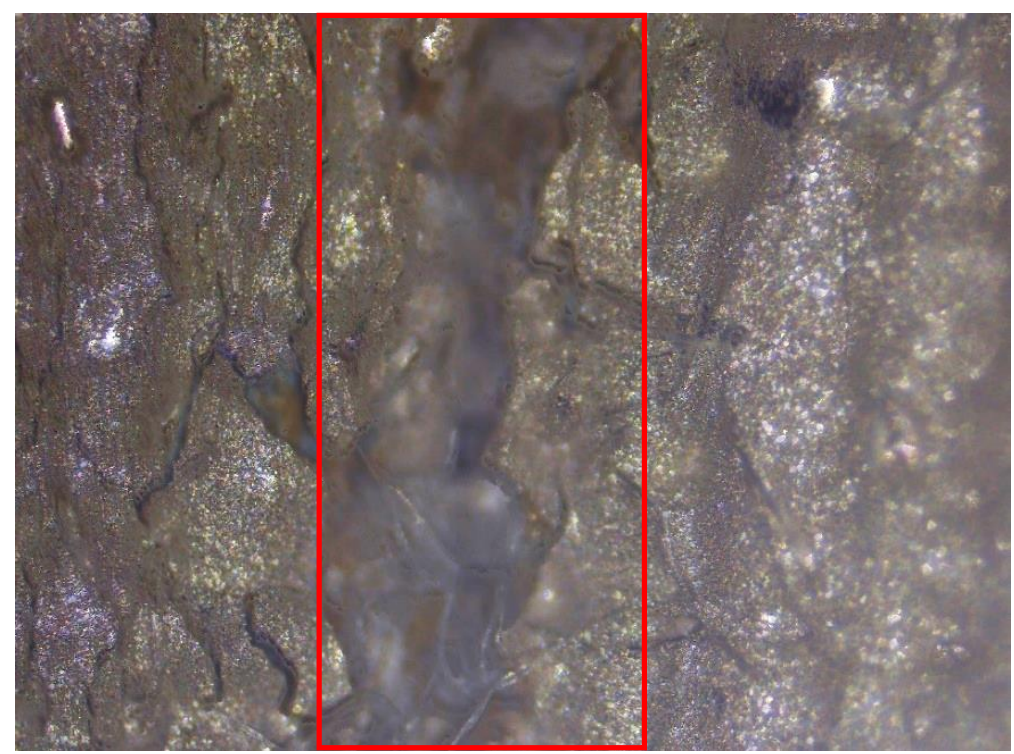

Figure 5 Cracks formation on CO plasma 825 sample $5 x$ magnified 


\begin{tabular}{|l|c|c|c|c|c|c|}
\hline \multirow{2}{*}{ Sample } & \multicolumn{2}{|c|}{$\begin{array}{c}\text { Before washing } \\
\text { (0ws) }\end{array}$} & \multicolumn{2}{c|}{$\begin{array}{c}\text { After 5 washing } \\
\text { cycles (5ws) }\end{array}$} & \multicolumn{2}{c|}{$\begin{array}{c}\text { After 10 washing } \\
\text { cycles (10ws) }\end{array}$} \\
\cline { 2 - 7 } & $\begin{array}{c}\text { Without } \\
\text { plasma }\end{array}$ & $\begin{array}{c}\text { With } \\
\text { plasma }\end{array}$ & $\begin{array}{c}\text { Without } \\
\text { plasma }\end{array}$ & $\begin{array}{c}\text { With } \\
\text { plasma }\end{array}$ & $\begin{array}{c}\text { Without } \\
\text { plasma }\end{array}$ & $\begin{array}{c}\text { With } \\
\text { plasma }\end{array}$ \\
\hline PES + PE825 & - & - & 3.20 & 2.90 & 2.50 & 1.50 \\
\hline PES + PE 828 & 3.10 & 3.45 & 2.75 & 2.85 & 2.70 & 2.15 \\
\hline PA + PE 825 & - & - & 3.30 & 2.95 & 3.30 & 3.00 \\
\hline PA + PE 828 & 2.55 & 3.20 & 2.80 & 2.95 & 3.25 & 3.30 \\
\hline CO + PE 825 & - & - & 2.85 & 3.40 & 2.60 & 2.65 \\
\hline CO + PE 828 & 3.45 & 2.95 & 2.70 & 2.80 & 2.60 & 2.50 \\
\hline CO/PES + PE 825 & - & - & 3.00 & 3.20 & 2.65 & 1.95 \\
\hline CO/PES + PE 828 & 2.95 & 3.10 & 2.75 & 2.70 & 2.20 & 2.50 \\
\hline
\end{tabular}


Table II Resistance value on fabrics, in $\Omega$

\begin{tabular}{|l|c|c|c|c|c|c|}
\hline \multirow{2}{*}{ Sample } & \multicolumn{2}{|c|}{$\begin{array}{c}\text { Without washing } \\
\text { (0ws) }\end{array}$} & \multicolumn{2}{c|}{$\begin{array}{c}\text { After 5 washing } \\
\text { (5ws) }\end{array}$} & \multicolumn{2}{c|}{$\begin{array}{c}\text { After 10 washing } \\
\text { (10ws) }\end{array}$} \\
\cline { 2 - 7 } & $\begin{array}{c}\text { Without } \\
\text { plasma }\end{array}$ & $\begin{array}{c}\text { With } \\
\text { plasma }\end{array}$ & $\begin{array}{c}\text { Without } \\
\text { plasma }\end{array}$ & $\begin{array}{c}\text { With } \\
\text { plasma }\end{array}$ & $\begin{array}{c}\text { Without } \\
\text { plasma }\end{array}$ & $\begin{array}{c}\text { With } \\
\text { plasma }\end{array}$ \\
\hline PES + PE 825 & 90 & 80 & 126 & 43 & 45 & NC \\
\hline PES + PE 828 & 190 & 130 & 136 & 186 & NC & NC \\
\hline PA + PE 825 & 70 & 75 & NC & NC & NC & NC \\
\hline PA + PE 828 & 200 & 190 & NC & NC & NC & NC \\
\hline CO + PE 825 & 90 & 100 & 76 & 105 & 140 & 70 \\
\hline CO+ PE 828 & 80 & 100 & 109 & 160 & 160 & NC \\
\hline CO/PES + PE 825 & 90 & 100 & 160 & 125 & 50 & 76 \\
\hline CO/PES + PE 828 & 160 & 170 & 170 & 230 & NC & NC \\
\hline
\end{tabular}


Table III Resistance value on multifibre fabrics Ink 825, in $\Omega$

\begin{tabular}{|l|c|c|c|c|c|c|}
\hline \multirow{2}{*}{ Sample } & \multicolumn{2}{|c|}{$\begin{array}{c}\text { Without washing } \\
\text { (0ws) }\end{array}$} & \multicolumn{2}{c|}{$\begin{array}{c}\text { After 5 washing } \\
\text { (5ws) }\end{array}$} & \multicolumn{2}{c|}{$\begin{array}{c}\text { After 10 washing } \\
\text { (10ws) }\end{array}$} \\
\cline { 2 - 7 } & $\begin{array}{c}\text { Without } \\
\text { plasma }\end{array}$ & $\begin{array}{c}\text { With } \\
\text { plasma }\end{array}$ & $\begin{array}{c}\text { Without } \\
\text { plasma }\end{array}$ & $\begin{array}{c}\text { With } \\
\text { plasma }\end{array}$ & $\begin{array}{c}\text { Without } \\
\text { plasma }\end{array}$ & $\begin{array}{c}\text { With } \\
\text { plasma }\end{array}$ \\
\hline Acetate + PE 825 & 40 & 40 & 45 & 42 & 75 & 52 \\
\hline Acetate+ PE 828 & 40 & 60 & 40 & 52 & 52 & 80 \\
\hline Cotton + PE 825 & 50 & 55 & 42 & 41 & 50 & 56 \\
\hline Cotton + PE 828 & 50 & 60 & 43 & 51 & 47 & 46 \\
\hline $\begin{array}{l}\text { Polyamide + PE } \\
\text { 825 }\end{array}$ & 60 & 70 & 116 & 64 & NC & 89 \\
\hline $\begin{array}{l}\text { Polyamide + PE } \\
\text { 828 }\end{array}$ & 60 & 80 & 49 & 56 & 64 & 82 \\
\hline Polyester + PE 825 & 40 & 40 & 42 & 40 & 38 & 46 \\
\hline Polyester + PE 828 & 40 & 50 & 40 & 45 & 42 & 51 \\
\hline Acrylic + PE 825 & 50 & 50 & 41 & 43 & 98 & 100 \\
\hline Acrylic + PE 828 & 40 & 75 & 40 & 62 & 66 & 80 \\
\hline Wool + PE 825 & 50 & 45 & 42 & 43 & 40 & 90 \\
\hline Wool + PE 828 & 50 & 50 & 41 & 55 & 66 & 60 \\
\hline
\end{tabular}

